\title{
Effect of Application of Health Belief Model on females' Knowledge and Practice regarding the premarital counseling
}

\author{
Shaimaa,H. Mohamady ${ }^{1}$, Samah, A.E.said ${ }^{2} \&$ Hanan, A. EL Sayed ${ }^{3}$ \\ ${ }^{1}$ Lecturer of Maternal and Newborn Health Nursing, Faculty of Nursing, Helwan University, Egypt \\ ${ }^{2}$ Lecturer of Obstetric and Woman Health Nursing, Faculty of Nursing, Benha University, Egypt \\ ${ }^{3}$ Lecturer of Community Health Nursing, faculty of nursing, Benha University, Egypt
}

\begin{abstract}
Background: Premarital counselling is one of the most important strategies for prevention of genetic disorders, congenital anomalies and several medical, psychosocial marital problems.

Aim of the study was to evaluate the effect of application of Health Belief Model on females' knowledge and Practice regarding premarital counseling.

Design: a quasi-experimental design was used.

Setting: the current study was conducted at administrative building at Benha University.

Sample: A purposive sample of 340 females out of $(n=2306)$ and randomly divided into an intervention group (170) and control. Three tools were used for data collection; 1) a structured interview questionnaire consisted of socio-demographic characteristics and females' knowledge regarding premarital counselling. 2) Health belief model questionnaire. 3) Questionnaire to assess intention to practice of premarital counselling.

Results: There was no significant difference between both groups in general characteristics, although there was statistically significant difference in females' knowledge, health beliefs and intention to practice premarital counselling in the intervention group compared to the control group two months after The application of health beliefs model $p \leq 0.001$. There was a positive highly statistically significant correlation between total knowledge and total intention scores in both groups before and after two months of premarital counselling. Conclusion: Health Belief Model was effective in improving females' knowledge, health beliefs and health Practice. Recommendation: Dissemination of premarital counselling based on health belief model among females to increase awareness.
\end{abstract}

Keywords: Behavior, Health Beliefs Model, premarital counseling.

\section{Introduction}

Marriage is an important event in a females' life. It is family building from which an individual enters a new phase in building emotional and social relations. It should ensure protection of couples from genetic and infectious diseases to build a happy and stable family functioning successfully. Hereditary or contagious diseases can disturb life leading to psychological, social and economic problems as well as medical complications with reflection on female, the family and the society (1)

Approximately 4 million babies are born each year. About 3\% - 4\% will be born with a genetic disease or major birth defect. Approximately $1 \%$ of all babies will be born with chromosomal abnormality, which can cause physical problems and mental retardation; more than $20 \%$ of infant deaths are caused by birth defects or genetic conditions (2).

Premarital counselling is that form of counselling which centres on the interpersonal relationship of a couple, helps female to evaluate relationship in view of approaching marriage and acquaints with ways of build a happy and successful marriage. Premarital counselling will help increase female likelihood for happiness because identify couples fears, values, beliefs, needs, and desires and learn how to communicate. (3).

Premarital education and couples counselling is to be some of the most effective prevention programs for couples as it considered a way to lower the chances of divorce and increase couple satisfaction after marriage (4). It can provide an opportunity to intervene according to the identified risk. This intervention includes vaccination, nutrition, genetic counselling, advice regarding contraception, counselling regarding chronic disease, treatment of infections and decrease teratogenic risk (5).

In addition, a premarital test is considered as a test that provides the base line health assessment of the prospective married couples and is defined as a test in which potential bride and the groom are tested for positive health, genetic, infectious and blood transmitted diseases to prevent any risk of transmitting any disease to each other and children (6).

Premarital counselling can help couples improve relationships before marriage. Through premarital counselling, couples are encouraged to discuss topics related to marriage, such as: communication, beliefs, values, roles in marriage, family relationships, decision-making, time spent together. The primary goals of 
premarital counselling includes: increasing stability and satisfaction developing the couple's communication skills, enhancing the companionship and promise to the relationship, enhancing intimacy between the couple, introducing and implementing problem-solving and decision-making abilities in the capacities of finances and marital responsibilities ( 7 )

A Health Belief Model (HBM) has been used extensively to assess health-related beliefs regarding protective behaviours. It is a cognitive model attempting to identify the patterns of health behaviours. The model can be adapted to counselling behaviour if one views complications as a state to avoid. Females vary in strength of desire to do premarital counselling and perception of costs and benefits of premarital counselling (8).

Health Belief Model composed of four main constructs. First, perceived susceptibility to realize and believe that they are exposed to the risk. Second, perceived severity: to understand and belief that the disease is serious public health problem, and it can lead to serious complications. Third, perceived barriers: to identify physical, psychological or financial, barriers that can hinder healthy behaviours so that the person can overcome it to assume healthy behaviour. Fourth, perceived benefits: it refers to the insight of the constructive consequences that are caused by a specific act. In addition, the model suggested that cues to action can act as behaviour stimuli [9].

Nursing is an integral part of the health care system and nurse's direct energies towards the promotion, maintenance \& restoration of health. Nurse play a valuable role in changing females believes, behaviours and providing health education about premarital counselling, discussing the benefits of premarital counselling, (10). Therefore, regular premarital counselling education based on HBM in order to prevent its related problems can be recommended as an essential approach or strategy in this field (11).

\section{Significance of The Study}

Nowadays premarital counseling is one of the most important strategies for prevention of genetic disorders, congenital anomalies and several medical, psychological marital problems (12). In Egypt genetic disorders are very common and highly prevalent in the general population. The prevalence of congenital and genetic disorders among infants and young children in Egypt is estimated to range from $2.8 \%$ in urban areas in metropolitan governorates to $8.4 \%$ in rural areas in (13)

The national Central Agency for Public Mobilization and Statistics (CAPMAS) publishes reports about divorce and marriage rates in Egypt, and in 2011 this government agency released statistics that there is one divorce in Egypt every 3 minutes, while there are 87 marriages every hour. Nurses and Professionals can facilitate the process and offer individuals, families with genetic disease the option of support groups and health education. So application of HBM can help to enhance female' knowledge, change health beliefs, and improve practice regarding premarital counselling.

\section{Aim of the study:}

This study undertaken to evaluate the effect of application of health belief model on females' knowledge and practice regarding premarital counselling through: -

> Assessing females' knowledge, health beliefs regarding premarital counselling, and practice premarital counselling.

$>$ Designing and implementing premarital counselling based on health belief model according to females' needs.

$>$ Evaluating the outcomes of application of health belief model.

\section{Hypothesis:}

The researchers hypothesized that

1- The studied females who apply health belief model would expect to improve knowledge about pre marital counselling compared to the control group.

2- The studied females who apply health belief model would expect Positive changes of health beliefs and practice toward pre marital counselling compared to the control group.

\section{Subjects and Method}

Study Design: A quasi- Experimental design was utilized to fulfil the aim of this study.

Setting: The study was conducted at administrative building at Benha University.

Sample: Purposive sample of 340 females out of $(n=2309)$ were included in the current study according to inclusion criteria females age 20years and more than 30 years, engaged females who are accepted to participate in the research, exclusion criteria; females who currently married. The sample was randomly divided into an intervention group (170) and control group (170). Sample size was calculated according to the following equation Yamane formula (1967) (14). The formula is given as: 
Effect of Application of Health Belief Model on females' Knowledge and Practice regarding the....

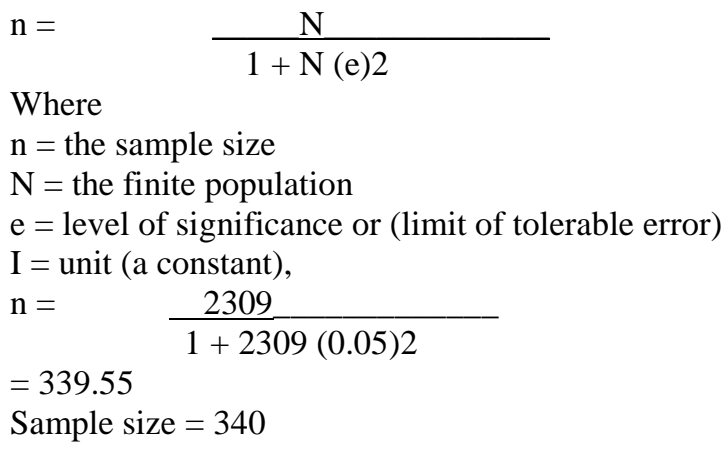

\section{Tools of Data Collection}

Three tools were used for data collection

First tool: - A self-administered questionnaire which was developed by the researchers in Arabic language after reviewing of related literature. It encompassed two main parts:

Part I: Socio-Demographic characteristics: age, level of education, residence and monthly income.

Part II: Knowledge of the studied sample regarding premarital counselling (pre/post format). It included twenty one multiple choice questions which divided into three sections. Section (1) pertained to assess females' knowledge about premarital counseling, it consisted of (seven) questions (definition, indications, risk factors, important, component, methods of effective communication, physical examination). Section (2) pertained to assess females' knowledge about the premarital health screening, it consisted of (nine) questions as (meaning of premarital screening, who need premarital screening, purpose, important the premarital tests, time of beginning premarital screening, frequency of, preparations needed before screening, what meant by abnormal premarital tests, and follow up to reduce the risks of serious complications ). Section (3) included knowledge concerning premarital vaccination, it consisted of (five) questions as (value of vaccines, target population for vaccines, recommended age group for taking vaccines, type of vaccines).

Scoring: A scoring for female knowledge regarding premarital counseling was consisted of given correct answer was scored "one" and the incorrect "zero". The knowledge score was calculated by adding the scores for the correct answers. The total possible score ranged from 0 to 21 and means and standard deviations were calculated. The higher scores reflect higher levels of knowledge about premarital counseling.

Second tools: - The HBM was adapted from Goodyear ,2015(15). Modification was done by the researchers on Arabic language. The HBM sub constructs which used in this study were perceived susceptibility (five items), perceived severity to premarital counselling (five items), perceived barriers (ten items), and perceived benefits (five items).

\section{The Scoring System of Health Belief Model:}

The questionnaire included 25 items on a5 point Likert scale ranging from 1(strongly disagree) to 5(strongly agree). Subscale mean scores were obtained by summing and averaging the items (range 1-5). Each subscale was calculated separately, and therefore four different scores were obtained for each subject. The possible total score range was (25-120), and a higher score indicated a more positive belief toward premarital counseling.

Third Tool: Questionnaire to assess intention to practice for premarital counselling behaviour (pre/post test format) was developed by the researchers in Arabic language after reviewing of related literature(12) which encompassing (2) questions: the first, doing premarital tests, and the second, receiving premarital vaccination.

Scoring system of intent to practice premarital counseling:

For each question, the responses were coded each intent to practice premarital counseling behaviours was scored "one", and each no intent was scored "zero". The intention score was calculated by adding the scores for the have intention responses.

Tools Validity and Reliability: The tools were reviewed for completeness, appropriateness, and legibility by an expert panel consisting of five obstetrics and female health nursing as well as community health nursing experts. The panel ascertained the face and content validity of the tools. The reliability was done by Cronbach's Alpha coefficient test which revealed that each of the three tools consisted of relatively homogenous items as indicated by the moderate to high reliability of each tool. The internal consistency of knowledge was 0.91 ; the total 25-items HBM was 0.81, with breakdowns by category: 0.72 (perceived susceptibility to the disease), 
0.83(perceived severity of the disease), 0.86 (perceived benefits of premarital counselling), 0.86 (perceived barriers of premarital prevention), and intention to practice premarital counseling behaviours was 0.79 .

Ethical Considerations: An explanation of the study aim and process were given to every eligible female in both groups, and then an oral consent was obtained from each female, strict confidentiality was ensured for any obtained information. Each female was informed the study do not entail any harmful effect, participation is voluntary. Withdraws from the study at any time and withdraws not affect the care provided. Moreover, the collected data were away from the moral and religious aspects of the enrolled participants.

Pilot Study: The pilot study was carried out on ten percent of the total sample (23 females) to ascertain the relevance, clarity, applicability of the tools, and to detect any problems peculiar to the statements. Also, the pilot study helped to estimate the time needed to complete the questionnaires. According to the results of the pilot study no modifications were done. Females involved the pilot study was excluded in the main study sample.

Field Work: A written official letter was obtained from the Dean of the Faculty of Nursing, Benha University and delivered to the Secretary General of Benha University in order to obtain the statistical numbers of females enrolled within administrative building of Benha University. The previous mentioned setting was visited by the researchers three days/week. The study was carried out through four phases: assessment, planning, implementation, and evaluation. These phases were carried out from beginning of April 2016 to the end of September 2016, covering along a period of six months.

Assessment Phase:- The researchers approached and interviewed each female individually in both control and intervention groups, explained the purpose and procedures of the study, and asked for her participation. Upon a verbal consent to participate, the females were handed the self-administered questionnaire to assess general characteristics and knowledge regarding premarital counseling, health belief model, and questionnaire to assess intention to practice and asked to fill it. The data obtained during this phase constituted the baseline for further comparisons to evaluate the effect of health belief model. To avoid cross contamination of information between both groups, control group was assessed first. Average time for the completion of each female interview was around (30-45 minutes). A number of interviewed females / week ranged from 13-15 females.

Planning and Implementation Phase: Based on the needs identified in the assessment phase from the intervention group, and reviewed literature, the researchers developed health belief model about premarital counseling constructs with simple Arabic language to suit females' level of understanding, which aimed to improve females' knowledge, modify their health beliefs, and empower them to take health decisions for premarital screening practice. It emphasized the areas of major deficiency in females knowledge about important of premarital counseling health beliefs and intention to practice for premarital screening behaviors such as meaning of premarital screening, needed, risk factors, signs and symptoms, diagnosis, methods of treatment and prevention, types, time, purposes, benefits and vaccination (benefits, safety, and availability, recommended age for vaccination. Premarital intervention booklet distributed to each female in intervention group.

Evaluation Phase: After two months, the effectiveness of the application of health beliefs model on knowledge, health beliefs and intention to practice premarital counseling was assessed through post test format.

Statistical Analysis: Data were verified prior to computerized entry. The Statistical Package for Social Sciences (SPSS version 20.0) was used for that purpose, followed by data analysis and tabulation. Descriptive statistics were applied (e.g., mean, standard deviation, frequency and percentages). Test of significance (chi-square and independent $t$ test and paired $t$ test) were used to test the significant differences between two groups and to test the study hypothesis. Pearson correlation coefficients were used. A Statistically significant difference was considered at $\mathrm{p}$-value $\mathrm{p} \leq 0.05$, and a highly statistically significant difference was considered at $\mathrm{p}$-value $\mathrm{p} \leq$ 0.001 . 


\section{Result}

Table (1) Distribution of the studied sample according to their socio-demographic characteristics $n=340$.

\begin{tabular}{|c|c|c|c|c|c|c|}
\hline \multirow[t]{2}{*}{$\begin{array}{l}\text { Socio demographic } \\
\text { characteristics }\end{array}$} & \multicolumn{2}{|c|}{$\begin{array}{l}\text { Intervention } \\
\text { group } n=170\end{array}$} & \multicolumn{2}{|c|}{$\begin{array}{l}\text { Control group } \\
n=170\end{array}$} & \multirow[t]{2}{*}{$\mathrm{X} 2$} & \multirow[t]{2}{*}{ p value } \\
\hline & No & $\%$ & No & $\%$ & & \\
\hline \multicolumn{7}{|l|}{ Age (years) } \\
\hline 20 & 25 & 14.7 & 21 & 12.3 & \multirow{4}{*}{0.530} & \multirow{4}{*}{0.753} \\
\hline $21-25$ & 87 & 51.1 & 93 & 54.7 & & \\
\hline$\geq 26$ & 58 & 34.2 & 56 & 32.9 & & \\
\hline$\overline{M e a n} \pm$ SD & \multicolumn{2}{|c|}{$23.96 \pm 0.88$} & \multicolumn{2}{|c|}{$23.94 \pm 1.04$} & & \\
\hline \multicolumn{7}{|l|}{ Level of education : } \\
\hline Primary education & 70 & 41.2 & 69 & 40.6 & \multirow[t]{3}{*}{0.440} & \multirow[t]{3}{*}{0.673} \\
\hline Secondary education & 88 & 51.7 & 86 & 50.6 & & \\
\hline University education & 12 & 7.0 & 15 & 8.8 & & \\
\hline \multicolumn{7}{|l|}{ Residence : } \\
\hline Urban & 71 & 41.7 & 68 & 40.0 & \multirow[t]{2}{*}{58.3} & \multirow[t]{2}{*}{58.3} \\
\hline Rural & 99 & 58.3 & 102 & 60.0 & & \\
\hline \multicolumn{7}{|l|}{ Monthly income } \\
\hline Sufficient & 45 & 26.5 & 48 & 28.3 & \multirow[t]{2}{*}{0.246} & \multirow[t]{2}{*}{0.623} \\
\hline Insufficient & 125 & 73.5 & 122 & 71.7 & & \\
\hline
\end{tabular}

${ }^{\text {ns }}$ not statistically significant at $\mathrm{p} \geq 0.05$

$\mathrm{t}=$ independent $\mathrm{t}$ test

Table (1) shows socio demographic characteristics of the studied sample. It was clear that more than half $51.1 \%$ and $54.7 \%$ of both intervention and control groups respectively were in age group $21-25$ years with a mean age of $23.96 \pm 0.88$ years and $23.94 \pm 1.04$ years respectively. Regarding level of education the intervention group 51.7\% and control group 50.6\% were secondary education. As regards residence, the intervention group $58.3 \%$ and control group $60.0 \%$ were living in rural areas. As far as monthly income, less than three quarters of the intervention and control groups $73.5 \%$ and $71.7 \%$ respectively had insufficient income. There was no statistically significant difference between intervention and control groups regarding socio demographic characteristics, which mean that the two groups under study are homogenous.

Table (2) Mean scores of the studied sample' knowledge regarding premarital counseling in the intervention and control groups before and after intervention $n=340$.

\begin{tabular}{|c|c|c|c|c|c|c|c|c|c|}
\hline \multirow{3}{*}{$\begin{array}{l}\text { Knowledge } \\
\text { items }\end{array}$} & \multirow{3}{*}{$\begin{array}{l}\text { Maximum } \\
\text { score }\end{array}$} & \multicolumn{4}{|l|}{ Before } & \multicolumn{4}{|l|}{ After } \\
\hline & & $\begin{array}{l}\text { Intervention } \\
\text { group } n=170\end{array}$ & $\begin{array}{l}\text { Control } \\
\text { group } \\
\text { n=170 } \\
\end{array}$ & t test & p value & $\begin{array}{l}\text { Interventio } \\
\text { n group } \\
\mathrm{n}=170\end{array}$ & $\begin{array}{l}\text { Control } \\
\text { group } \\
\text { n=170 } \\
\end{array}$ & t test & p value \\
\hline & & Mean \pm SD & Mean \pm SD & & & Mean \pm SD & Mean \pm SD & & \\
\hline $\begin{array}{l}\text { Premarital } \\
\text { counselling }\end{array}$ & 7 & $1.19 \pm 0.86$ & $1.12 \pm 0.98$ & 0.671 & 0.503 & $6.40 \pm 0.84$ & $1.22 \pm 1.56$ & 45.532 & $\begin{array}{l}0.000 * \\
*\end{array}$ \\
\hline $\begin{array}{l}\text { Premarital } \\
\text { health } \\
\text { screening }\end{array}$ & 9 & $1.65 \pm 1.36$ & $1.51 \pm 1.39$ & 0.902 & 0.368 & $7.86 \pm 0.95$ & $1.61 \pm 1.23$ & 39.452 & $\begin{array}{l}0.000 * \\
*\end{array}$ \\
\hline $\begin{array}{l}\text { Premarital } \\
\text { vaccination }\end{array}$ & 5 & $0.05 \pm 0.22$ & $0.03 \pm 0.16$ & 1.176 & 0.240 & $4.37 \pm 0.83$ & $0.04 \pm 0.21$ & 63.598 & $\begin{array}{l}0.000^{*} \\
*\end{array}$ \\
\hline
\end{tabular}

The test used independent $t$ test between intervention and control group.

$* *$ A highly statistical significant difference $(\mathrm{p} \leq 0.001)$

Table (2) reveals that, there was no statistically significant difference between both intervention and control groups before premarital counseling regarding knowledge about premarital counselling, premarital health screening and premarital vaccination. Meanwhile, after two months mean scores of intervention group was higher than in control group $\mathrm{P}$-value $<0.001$. 
Table (3) Mean scores of constructs of Health Belief Model in the intervention and control groups before and after Intervention . $\mathrm{n}=340$

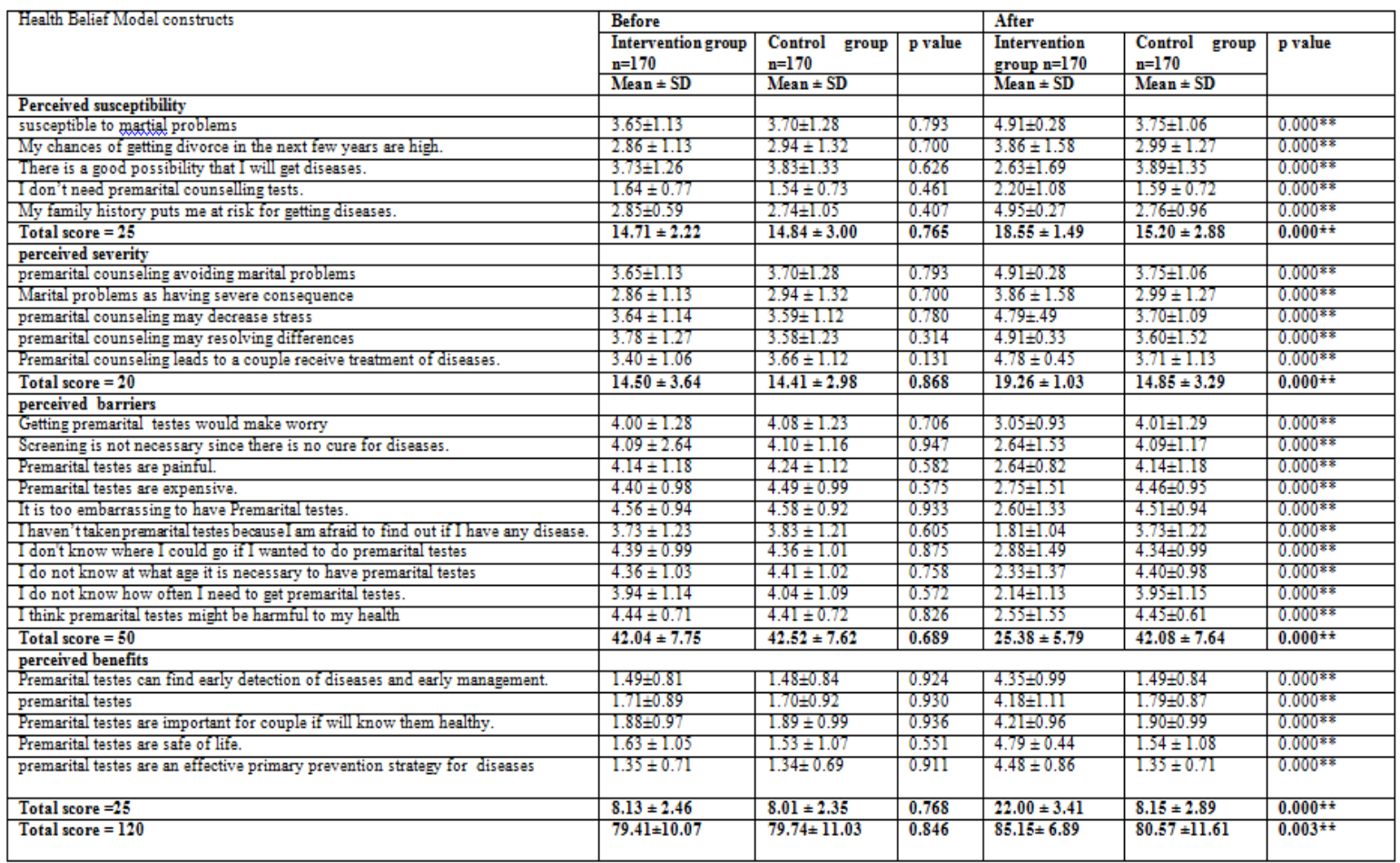

The test used independent $\mathrm{t}$ test between intervention and control group. **A highly statistical significant difference $(\mathrm{p} \leq 0.001)$

Table (3) clarifies that, the mean scores of all health belief sub constructs before and after two months of premarital counseling preventive program within and between intervention and control groups. Before premarital counselling application, the mean scores of health beliefs in the two groups were similar in all items of sub constructs with there was no statistically significant difference. However, after two months of premarital counseling application, the mean scores of perceived susceptibility, perceived severity, and perceived benefits of early detection were significantly higher in the intervention group compared to control group. The results also confirmed that the mean scores of perceived barriers of early detection were significantly decreased in intervention group rather than the control group.

Table (4) Mean differences between intervention and control groups regarding their intention to practice premarital counseling before and two months after application implementation $n=340$

\begin{tabular}{|l|l|l|l|l|}
\hline \multicolumn{1}{|c|}{ Variables } & \multicolumn{3}{l|}{ Total intention score } \\
\cline { 2 - 5 } & $\begin{array}{l}\text { Intervention } \\
\text { group } \mathrm{n}=170\end{array}$ & $\begin{array}{l}\text { Control group } \\
\mathrm{n}=170\end{array}$ & $\begin{array}{l}\text { Significance between } \\
\text { groups }\end{array}$ \\
\cline { 2 - 5 } & Mean $\pm \mathrm{SD}$ & Mean $\pm \mathrm{SD}$ & t-test & $\mathrm{p}$-value \\
\hline Before of implementation. & $6.21 \pm 1.13$ & $6.30 \pm 1.31$ & 0.581 & 0.562 \\
\hline $\begin{array}{l}\text { After two months of } \\
\text { implementation. }\end{array}$ & $11.72 \pm 3.72$ & $6.32 \pm 2.44$ & 14.972 & $0.000^{* *}$ \\
\hline $\begin{array}{l}\text { Significance within } \\
\text { group(p value) }\end{array}$ & $\begin{array}{l}\text { Intervention group: }(\mathrm{t} 2)=17.845\left(\mathrm{p}=0.000^{* * *}\right) \\
\text { Control group }(\mathrm{t} 2)=1.143(\mathrm{p}=0.254)\end{array}$ \\
\hline
\end{tabular}

$\left(\mathbf{t}_{1}\right)$ Independent $t$ test $\left(\mathbf{t}_{2}\right)$ Paired t test.

**A highly statistical significant difference $(\mathrm{p} \leq 0.001)$

Table (4) illustrates that, there was no statistically significant difference between both intervention and control groups before application implementation regarding intention to practice premarital counseling. Meanwhile, there was a highly statistically significant difference p-values $<0.001$ two months after application implementation was observed between the two groups. Also there was a highly statistically significant 
difference $\mathrm{p}<0.001$ before and after application implementation within the intervention group regarding their health behaviour to premarital counseling.

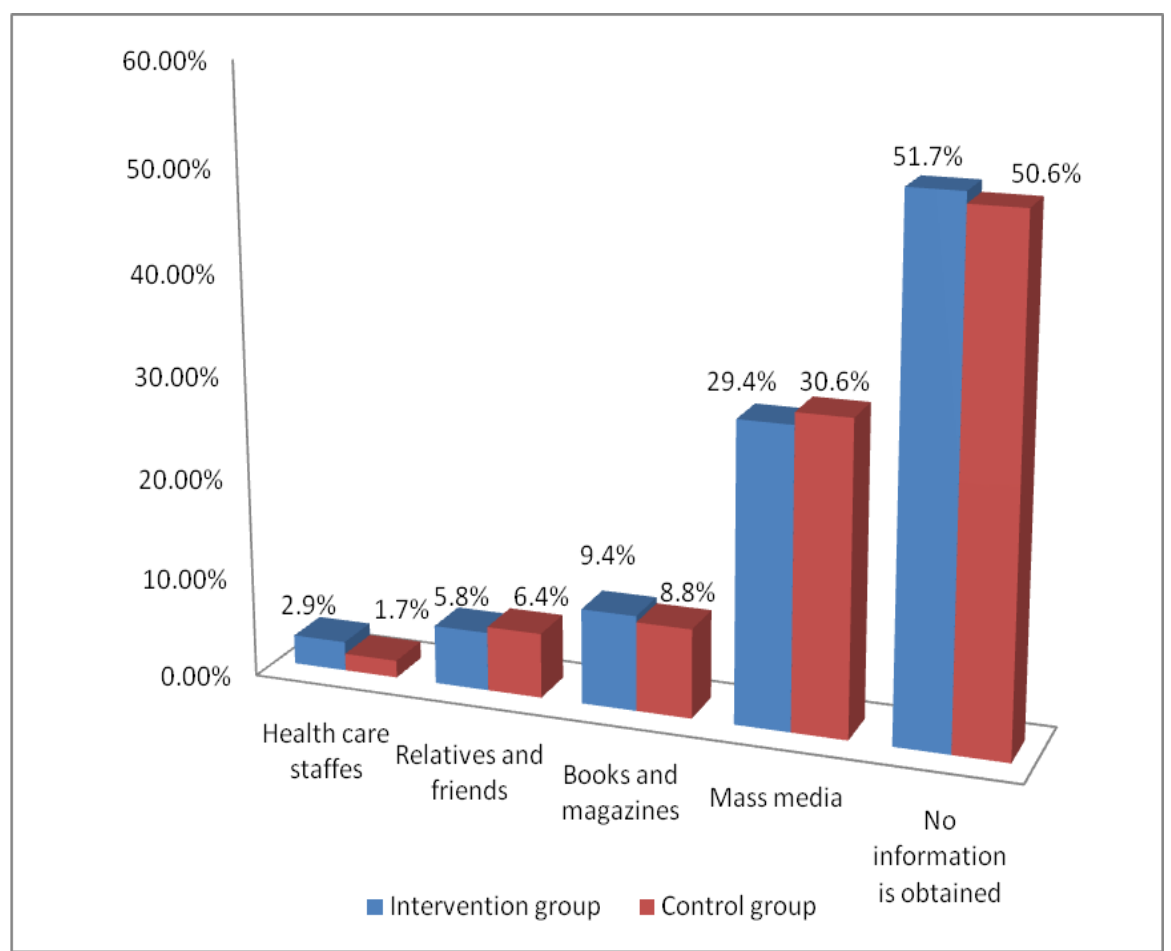

Figure (1) Distribution of the studied sample according to their source of information regarding premarital counseling $n=340$

Figure (1) illustrates that $51.2 \%$ and $50.6 \%$ of studied sample in the intervention and control groups respectively reported they had not obtained any information regarding premarital counseling from any sources. Meanwhile, $2.9 \%$ of the intervention group and $1.7 \%$ of control group obtained information from health care staff.

Table (5) Correlation coefficient between total scores of knowledge, health beliefs constructs and intention regarding premarital counseling in the intervention and control groups before and after two months intervention $\mathrm{n}=340$.

\begin{tabular}{|c|c|c|c|c|c|}
\hline \multicolumn{2}{|l|}{ Variables } & \multicolumn{4}{|c|}{ Total knowledge score } \\
\hline & & \multicolumn{2}{|c|}{ Intervention group $n=170$} & \multicolumn{2}{|c|}{ Control group $n=170$} \\
\hline & & $\mathrm{R}$ & $\mathrm{p}$ & $\mathrm{r}$ & $\mathrm{P}$ \\
\hline \multirow[t]{2}{*}{ Total health beliefs scores } & Before implementation & 0.656 & $0.000 *$ & 0.634 & $0.000 * *$ \\
\hline & $\begin{array}{l}\text { After two months of } \\
\text { implementation }\end{array}$ & 0.798 & $0.000 * *$ & 0.564 & $0.000 * *$ \\
\hline \multirow[t]{2}{*}{ Total intention score } & Before implementation & A & - & $\mathrm{a}$ & - \\
\hline & $\begin{array}{l}\text { After two months of } \\
\text { implementation }\end{array}$ & 0.612 & $0.000 * *$ & 0.221 & $0.001 * *$ \\
\hline
\end{tabular}

**Correlation is highly significant at $(\mathrm{p} \leq 0.01)$

a Cannot be computed because at least one of the variables is constant.

Table (5) show that, there was a positive highly statistically significant correlation between total knowledge and total health beliefs scores in both intervention and control groups before and after two months of premarital counseling. Moreover, there was a positive highly statistically significant correlation between total knowledge and total intention scores in both groups before and after two months of application implementation. 
Table (6) Correlation coefficient between total scores of knowledge and health beliefs Premarital counseling in the intervention and control groups before and after two months intervention $n=340$.

\begin{tabular}{|c|c|c|c|c|c|}
\hline \multicolumn{2}{|l|}{ Variables } & \multicolumn{4}{|c|}{ Total knowledge score } \\
\hline & & \multicolumn{2}{|c|}{ Intervention group $n=170$} & \multicolumn{2}{|c|}{ Control group $n=170$} \\
\hline & & $\mathrm{R}$ & $\mathrm{p}$ & $\mathrm{r}$ & $\mathrm{P}$ \\
\hline \multirow[t]{2}{*}{ Total health beliefs score } & Before of education & 0.657 & $0.000 * *$ & 0.640 & $0.000^{* *}$ \\
\hline & After two months of education & 0.859 & $0.000 * *$ & 0.675 & $0.000 * *$ \\
\hline
\end{tabular}

**Correlation is highly significant at $(\mathrm{p} \leq 0.01)$

Table (6) clarifies that, there was a positive highly statistically significant correlation between total knowledge and total health beliefs scores in both intervention and control groups before and after two months of application implementation $\mathrm{p} 0.000$.

Table (7) Correlation coefficient between total scores of intention and health beliefs premarital counseling in the intervention and control groups before and after two months intervention $n=340$.

\begin{tabular}{|c|c|c|c|c|c|}
\hline \multicolumn{2}{|l|}{ Variables } & \multicolumn{4}{|c|}{ Total intention score } \\
\hline & & \multicolumn{2}{|c|}{ Intervention group $n=170$} & \multicolumn{2}{|c|}{ Control group $n=170$} \\
\hline & & $\mathrm{R}$ & $\mathrm{P}$ & $\mathrm{r}$ & $\mathrm{P}$ \\
\hline \multirow[t]{2}{*}{ Total health beliefs score } & Before of education & $\mathrm{a}$ & - & $\mathrm{a}$ & - \\
\hline & After two months of education & 0.421 & $0.000^{* *}$ & 0.210 & $0.006^{* *}$ \\
\hline
\end{tabular}

** Correlation is highly significant at $(\mathrm{p} \leq 0.01)$

a Cannot be computed because at least one of the variables is constant.

Table (7) clarifies that, there was a positive highly statistically significant correlation between total intention and total health beliefs scores in both intervention and control groups before and after two months of application implementation $\mathrm{p} 0.000$.

\section{Discussion}

This study showed that, there was no a statistically significant difference between intervention and control groups in terms of age, educational level, residence, monthly income and work. These results mean that the two groups under study are homogenous. This finding is in accordance with Suk, et al., 2013 (16)who study on Korean female college revealed that there were no statistically significant differences between the studied groups regarding their characteristics. As well as Shahnazi et al., 2015 (17) who conducted a study to detect the impact of education intervention based on HBM on different health behaviour. They pointed out that, there was no significant difference between the intervention and the control groups.

The study revealed that there was highly statistically significant improvement in knowledge items in intervention group related to premarital counselling, important of premarital counselling, premarital examination and immunization than control group after two months of premarital counselling intervention application. These findings agree with at least four researches. First, Hayat, etal., 2016 (18) who had studied the effect of an education program based on health belief model on sex knowledge and behaviour in couples referred to marriage counselling in health care centre of Dezful city. He found that there was significant improvement of couple knowledge regarding all items in relation to sexual behaviours immediately after 3 months of application implementation. Second Abd Elfattah, etal., 2015 (19) who evaluate the effect of premarital genetic counseling on the knowledge and attitudes among unmarried female adolescents and found highly improvement in total score level of student's knowledge regarding premarital genetic counseling post intervention than before.

Third, Kepler, 2015 (20) who study the impact of premarital and couples counseling and found that premarital counselling was beneficial for those who participated. Of the fifteen participants who received premarital counselling, fourteen of them rated their marital satisfaction level and knowledge are high. Fourth Abd El-Ghany, 2010 (21) who study the knowledge and Attitude about Pre-Marital Counseling among Hadhramout University Students and his results revealed that only 5.5\% \& $22.5 \%$ of non-medical and medical groups of students respectively scored high level of knowledge about premarital counseling.

Also the current study results were consistent to what was reported in similar studies by Alkaldi, 2016 (22). The first, study knowledge and Attitude of Sultan Qaboos University Students in Oman towards premarital screening program and found the availability of premarital Screening in Oman but their knowledge was inadequate about its various aspects such as what it includes and what diseases it targets. The second study the knowledge and attitudes toward mandatory premarital screening among university students in North Jordan and found that, there was still a lack of knowledge about the thalassemia disease itself. So this improvement of knowledge post intervention in the our study reflect the impact of educational intervention on awareness 
accretion based on HBM and also attributed to the ability of the studied subjects to gain knowledge easily as more than half of them had secondary and university education also they are interested in the research topics .

Regarding The four main HBM constructs, the current study results showed a significant increase in the mean scores of perceived susceptibility on the intervention group compared to control group two months after application implementation. This result is compatible to Hayat, etal., 2016 (18) who found that the people's susceptibility has increased and suggested that perceived susceptibility must be increased by training before entanglement of disease. On the other hand Magda, et al., 2012(23) who had studied the effect of HBM based education on screening behaviours of breast cancer among females and Mahmoodi, et al., 2011 (24) who investigated "the impact of education using Health Belief Model on the awareness and attitude of male teachers regarding their participation in family planning in Iran showed no significant difference between intervention and control group in the perceived susceptibility after the educational intervention. This is due to the difference between the research topics and risk factors.

Additionally, the current findings also reported a significant increase in the mean scores of perceived severity among the intervention group compared to the control group two months after application implementation. This is congruent with Mohsen, 2016 (8) who study the effect of application of HBM on changing mothers' beliefs regarding birth spacing in rural areas and found that perception of seriousness of not using contraceptives of the sample is increased in the first post test than in the baseline. Also our study findings came in agrees with Mahmoodi et al.,2011 (24) who found that the mean perceived severity scores before and after education were $45.38 \pm 23.06$ and $53.27 \pm 1.21$, respectively. The results indicated a significant difference between the perceived threats scores before and after application.

These results are consistent with the findings of other researchers Rafaei et al,2010 (25) and also go in the same line with the findings of Nourani et al, 2010 (26) who study Sexual Satisfaction in Fertile and Infertile Females also the same results was documented by Yosif and Elsayed ,2014(27) who found that the mean scores of perceived severity increased in intervention group after self learning package based on Health Belief Model implementation with highly statistically significant difference observed between both groups.

In relation to perceived barriers the results of the current study revealed that, before application implementation, the mean scores perceived barriers in the two groups were similar However, after two months of premarital counselling preventive program, the mean scores of perceived barriers decreased in intervention group rather than the control group. It is encouraging to compare this study with that by Milhausen et al,2011 (28) in which stressed the positive effect of educational intervention on decreasing perceived barriers in his study of self guided, home-based intervention to promote condom use among young men.

This finding was similar to results Deptula and associates' studies who found that perceived barriers toward healthy sexual relationship were low and desirable. This finding is contrast with Reis et al., 2012 (29) who emphasized that the females had negative Pap smear barriers our results also did not go in the same line with Yosif and Elsayed ,2014(27) who found that after self learning package based on Health Belief Model implementation the mean scores of perceived barriers of performing Pap smear and HPV vaccination were significantly decreased in intervention group but not in the control group. This difference between our results and these findings is due to the difference between performing premarital counseling and performing Pap smear and perceived knowledge for participants about expensive and painful of Pap smear that increase their barriers toward performing Pap smear.

The present study findings indicated that the mean scores of perceived benefits to premarital increased in intervention group two months after application implementation with highly statistically significant difference observed between intervention and control group. This is consistent with the study of previously mentioned research of Hayat, etal., 2016 (18), who found that perceived benefits increased after education. Our results also consistent with the findings of other two researchers Yazdani,etal., 2013 (30) as perceived benefits in both studies were good.

Moreover, it was found that, none of both groups have intent to practice premarital counseling before application implementation. This may be attributed to the absence of designed educational program provided to these females about premarital counseling. In addition the coverage of premarital counseling services is still limited in Egypt and absence of counseling attitude in Egyptian culture. This results similar to Khalil, etal., 2014 (31) who study knowledge, beliefs and behaviour Intention about Premarital Screening among King Saud University Female Students in Riyadh and found that only $15 \%$ of the studied female students had good intention to premarital screening .participants refused or was not sure about carrying out premarital screening. They listed various barriers such afraid that the test results will not be in favour of their choice, they do not want to interfere with God's will, afraid of a positive result which will prevent continuation of marriage and because they think that their families will refuse continuation of marriage

Meanwhile, there was a highly statistically significant difference two months after application implementation was observed between the two groups . This may due to the effect of the educational program based on health belief model in helping the female employees in decision making regarding their health, and in 
having positive health behaviours. This as what found by Yosif and Elsayed, 2014(27) in their previously mentioned study. The present study result is also in the same line with some other recent studies Khoramabadi et al., 2016 (32) who studied the effect of education based on HBM on different health behaviours. They emphasized that changing the health belief is prerequisite for behaviour change

The results of the current study indicated that, the information about premarital counseling received from different sources as health care staff, relatives and friends, books and magazines and mass media. It was found that the females had not obtained any information regarding premarital counselling from any sources and more than quarter of females receive their information from mass media, also health care staff was the least external stimuli to practice premarital counselling. These findings go in the same line with Tehrani et al., 2014 (33) study. Who documented that the cues to action among his participant were information received from media. Also Raoofi, etal., 2016 (34) In his study, found that internet and friends were the best cues of actions for sexual health among couples and weak role of scientific books and experts in providing accurate information about sexual health was noticeable. Mean while this result isn't in accordance with the study of Abd El Aziz, etal.,2016 (35).The first found that Health team was the most prevalent external stimuli for current study participant to practice UGIs preventive behaviour. The second reported that around half of their participant had chosen health staff as the performance guide for them. This result reflect the importance of our educational program to be acues to practice premarital counseling beside mass media and to increase the educational role of health care staff to change behaviour of participants.

It was found that, there was a positive statistically significant correlation between knowledge and health beliefs as well as between knowledge and intention score in both intervention and control group before and two months after application implementation. These findings are in congruence with at least three studies Raoofi et al., 2016; (34). The first assessed correlation between knowledge, health belief constructs and the participants' intention of hepatitis B vaccination using Pearson and Spearman correlation coefficient. The second clarified that, there was the significant correlation between self-efficacy and desired health behaviours The third showed a significant correlation between knowledge and all HBM construct with health behaviour

Additionally, the present study results clarified that, there was a positive highly statistically significant correlation between total intention and total health beliefs scores in both intervention and control groups before and after two months of premarital counseling application implementation. This finding is consistent with previously mentioned study of Abd El Aziz, etal.,2016 (35) who found that there was a positive highly statistically significant correlation between health beliefs and health behavior in both intervention and control groups before and two months after application implementation. Also Juntasopeepun et al., 2012 (36) who highlighted that beliefs play a vital role in a person's decision to engage in health preventive behaviors.

\section{Conclusion}

The application of health beliefs model was effective in improving females' knowledge, health beliefs and intention to practice premarital counselling.

\section{Recommendations}

Based on results of the present study, the following recommendations can be suggested:

- Increase female's awareness about premarital counseling through regular educational program based on HBM.

- Provide females with instructional booklets about premarital counseling based on HBM to improve their knowledge and health belief.

- Vaccination should be recommended before marriage for females.

Further researches: - Replication of this study on a large sample and in different settings is recommended for generalization of results.

\section{References}

[1] Available from http://www.moh.gov.sa/HealthAwareness/Before marriage/Pages/default.aspx.

[2] Congenital anomalies Fact sheet Updated September (2016): Ministry of Health [MOHP] (2010). Standards of practice for integrated MCH/RH Services: First Edition. Available at: http://www.drguide.mohp.gov.eg/newsite/ELearning

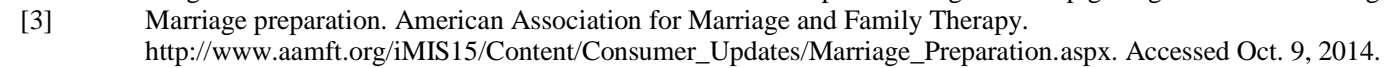

[4] Correia, P.S., Vitiello, P., Cabral, M.H., and Cardoso, A., (2013): Conceptions on genetics in a group of college students Community Genet; 4:115-123

[5] .Ahmed, S., (2011): Risk reduction of genetic disorders by pre-marital and neonatal screening. Eastern Bioethics and Life Sciences. Dubai, UAE. Retrieved May 20th, from http: //www.life sciences magazines.com.

[6] World Health Organization (2012): Health education: theoretical concepts, effective strategies and core competencies, WHO Regional Office for the Eastern Mediterranean, Cairo

[7] Grossman D, GrindlayK, Rick L, et al. Interest in overthe- counters access to oral contraceptives among females in the United States. 2013; 88(4): 544-552. Available from: http://www.contraceptionjournal.org/article/S00107824\%2813\%29001297/abstract 
[8] Mohsen,M.M.,. El-Abbassy,A.A.,. Khalifa,A.M.,( 2016): Effect of application of a Health Belief Model on changing mothers' beliefs regarding birth spacing in rural areas June 20: 54-66.

[9] Glanz, K., Rimer, B. and Viswanath, K.,(2008): Health Behaviour and Health Education: Theory, Research and Practice ,4th ed. San Francisco: Jossey-Bass; pp. 45-65.

[10] Abd Al Azeem,S.T., Elsayed,E.T., El Sherbiny,N,A., and Ahmed,L.A.,(2011): Promotion of knowledge and attitude towards premarital care: An interventional study among medical student in Fayoum University, Journal of Public Health and Epidemiology. 3(3):121-128.

[11] Mali, N.R., and Mali, R., (2014): Effect of structured education on knowledge regarding prevention of cervical cancer among A.N.M. students, International Journal of Science and Research, 3(3): 610-616

[12] Isah B.A.1, Yahaya Musa1, U.K Mohammed2, Ibrahim MTO3, Awosan KJ4, E.U., Yunusa.1.,(2016): Knowledge and Attitude Regarding Premarital Screening for Sickle Cell Disease among Students of State School of Nursing Sokoto, ISSN , issue (3).

[13] Abd- Al Raouf, R. (2010): Genetic services in Egypt: current situation and needs assessment. Institute of Postgraduate Childhood Studies. Ain Shams University Cairo Egypt.

[14] Yamane, Taro. (1967): Statistics, An Introductory analysis, 2nd Ed., New York: Harper and Row.

[15] Goodyear, G.(2015): Gynaecological infections, nursing in practice. Available at http://www.nursinginpractice.com/article/gynaecological-infections

[16] Suk, M., Bong, C., and Sun, K., (2013): Effects of a peer cervical cancer prevention education program on Korean female college students' knowledge, attitude, self-efficacy, and intention, Korean J Adult Nurs., 25 (6): 736-746.

[17] Shahnazi, H., Sabooteh, S., Sharifirad, G., Mirkarimi, K. and Hassanzadeh, A.(2015): The impact of education intervention on the Health Belief Model constructs regarding anxiety of nulliparous pregnant females, J Educ Health Promotion, Mar 27.

[18] Hayat,S.M.G., Karami,K.and Eisapareh,K.,(2016): The effect of an education program based on health belief model on sex knowledge and behavior in couples referred to marriage counseling Dezful, Iran 5(1).

[19] Abd Elfattah., H., Soliman1, S.M., and Amin,F.M., (2015): Premarital Genetic Counselling among Female Adolescents Students, Journal of American Science:11(6): 173-181.

[20] Kepler, A., (2015):"Marital Satisfaction: The Impact of Premarital and Couples Counselling" Master of Social Work Clinical Research Papers. Paper 474. http://sophia.stkate.edu/msw_papers/474

[21] Abd El-Ghany,G,M., Gad,A,H., and Al-Haddad,A,M.,(2010): Knowledge and Attitude about Pre-Marital Counseling among Hadhramout University Students, July

[22] Alkhaldi, S.M., Khatatbeh, M.M., Berggren, V.E.,and Taha, H.A., ( 2016): Knowledge and Attitudes Toward Mandatory Premarital Screening Among University Students in North Jordan Hemoglobin. 40(2):118-24

[23] Magda, M., Mohsen,M.M., El-Abbassy,A.A., and Khalifa,A.M.,(2016): the effect of application of HBM on changing mothers' beliefs regarding birth spacing in rural areas, Vol. 4, No. 3

[24] Mahmoodi, A., Kohan, and M., Azar, F., (2011): The impact of education using Health Belief Model on awareness and attitude of male teachers regarding their participation in family planning. Journal of Jahrom University of Medical Sciences. 9 (3). Available from: http://jmj.jums.ac.ir/files/site1/user_files_204932/eng/admin-A-10-1-80-a0edd8a.pdf

[25] Rafaei Shirpak, K.h., Chini Chian, M. and Eftekhar Ardabili, H., (2010): Pour Reza A, Ramezankhani A. Educational need assessment of sexual health among females referring family planning unite in Tehran Health Care Centers. Payesh; 9(3): 251-60. Nourani, S.h., Jonaidy, E., Shakeri, M.T.,and Mokhber, N.,(2010): Sexual Satisfaction in Fertile and Infertile Females Attending

[26] Nourani, S.h., Jonaidy, E., Shakeri, M.T., and Mokhber, N.,(2010): Sexual Satisfaction in Fertile and Infertile Females Attending
State Clinics in Mashad. Journal of Reproduction \& Infeitility; 10(41): 269-77. Yossif,H.A., and Elsayed,H.A., (2014): Effect of Self Learning Package Based on Health Belief Model on Cervical Cancer Prevention. IOSR Journal of Nursing and Health Science. 3 ( 6) : PP 77-88.

[28] Milhausen, R.R., Wood, J., Sanders, S.A., Crosby, R.A., Yarber, W.L., and Graham, C.A.,(2011): A novel, self guided, homebased intervention to promote condom use among young men: a pilot study. Journal of Men's Health,8(4): 274-281.

[29] Reis, N., Bebis, H., Kose, S., Sis, A., Engin, R., and Yavan,T.,(2012): Knowledge, behavior and beliefs related to cervical cancer and screening among Turkish females. Asian Pacific J Cancer Prevention, 13, 1463-1470.

[30] Yazdani, R. Zamani-Alavijeh, F. Kheiriat, M. Shafiee, A., and Arjmandzadegan, M., (2013): Factors associated with preventive behaviors of hepatitis B among high school girls using the health belief model. Daneshvar Medicine; 20: 1-12

[31] Khalil1,E.F., Abdelkader,S.M., Alsaeed,M.D., and Alshahrany,M.N., (2014): Knowledge, Beliefs and Behaviour Intention about Premarital Screening among King Saud University Female Students in Riyadh Sch. J. App. Med. Sci., 2(5E):1797-1805.

[32] .Khoramabadi, M. Dolatian, M. Hajian, S., Zamanian, M.,Taheripanah, R., Sheikhan, Z., Mahmoodi, Z. and Seyedi-Moghadam, A. (2016): Effects of education based on health belief model on dietary behaviors of Iranian pregnant females, Glob J Health Sci, 8(2): 230-239.

[33] Tehrani, FJ., Nikpour, S., Kazemi., E.A., Sanaie N. and Panahi, S.A.,(2014): The effect of education based on health belief model on health beliefs of females with urinary tract infection, Int J Community Based Nursing Midwifery. 2(1):2-11

[34] Raoofi,A., Hatefnia,E., Kazemnejad, A., and Alavian,S.M.,(2016): Health beliefs in hepatitis B vaccination among pre-marriage females, Biomedical Research; 27 (1): 116-122.

[35] Abd El Aziz,M.S., Ibrahim,H.A., and Elgzar,W.T., (2016): Effect of Application of Health Belief Model on Pregnant Females' Knowledge and Health Beliefs Regarding Urogenital Infections, IOSR Journal of Nursing and Health Science, 5( 5) Oct.), 34-44

[36] Juntasopeepun, P., Davidson, P., Suwan, N., Phianmongkhol, Y. and Srisomboon, J.,(2012): Human Papillomavirus vaccination intention among young females in Thailand, Asian Pacific J Cancer Prev, 13(1), 3213-3219. 